As a result of these and further deliberations, the following points can be made.

(a) The College has no available accommodation at its present site.

(b) Revenue implications could not be highly prioritised by the College.

(c) The College should support the principle of local museums where disparate exhibits, such as artefacts and medical records, might be displayed without decontextualisation.

G. E. BerRios

Honorary Librarian

The Royal College of Psychiatrists

\section{Locum consultant experience}

\section{DeAr SIRS}

My first locum consultant job was in the second year of my senior registrar training. It was out of financial necessity that I reluctantly worked during my annual leave. I have since done regular short-term locum consultant jobs, first as a senior registrar, now as a consultant, at least once a year. I would like to share some of the positive aspects of taking up a locum post, more specifically with senior registrars in the third and fourth year of training.

Leaving aside the financial reason, usually the main factor in taking such an appointment, there are other advantages. It gives an opportunity to have responsibility on a short-term basis. It is a testing time and one's strengths and weaknesses become apparent. It provides self-evaluation and insight to further training needs. It provides an opportunity to study and work in other services, to use personal resources to adjust to new rules, professionals, patients and managers and to study the quality of different consultant jobs. It also boosts confidence, selfreliance and belief in one's ability, and helps to acquire the necessary refinement before taking up a permanent consultant post.
It is important to take the job seriously, give one's best and make sure one enjoys it. There is less stress over services worries and one can leave a mark with new suggestions, thoughts and enthusiasm.

The job can be taken as a break, a chance to see a different part of the country, to make new acquaintances among fellow professionals and colleagues. Evenings can be long away from one's friends but gives a chance to catch up on light reading and refiection on present and future life. It is also an opportunity before taking one's ultimate appointment to polish the curriculum vitae which you need to submit for locum jobs. I would wholeheartedly recommend senior registrars in their third and fourth year to try at least one or two jobs for two to three weeks duration before they finally take up a consultant post. They will find it a very rewarding experience.

Hollymoor Hospital

A. JAWAd ShIEkH

Northfield

Birmingham B31 5EX

\section{The use of car telephones by psychiatrists}

Dear Sirs

Will there be more accidents on the road if psychiatrists have telephones in their cars? (Psychiatric Bulletin, 1992, 16, 756-757)?

In a previous post on duty for an adolescent unit I carried a mobile phone. On those occasions when I was called while driving (which was often) I learnt how important it was to pull in before answering. Some of the most hazardous driving I have seen is by BMW drivers on the phone. Will I now also have to watch out for Volvo drivers?

Child \& Family Psychiatric Unit

LAURENCE SHELDON

5 Collingham Gardens

London SW5 OHR 